Pacific Journal of Mathematics

COUNTEREXAMPLES IN THE BIHARMONIC
CLASSIFICATION OF RIEMANNIAN 2-MANIFOLD 


\title{
COUNTEREXAMPLES IN THE BIHARMONIC CLASSIFICATION OF RIEMANNIAN 2-MANIFOLDS
}

\author{
Leo Sario and Cecilia Wang
}

\begin{abstract}
Crucial counterexamples in the biharmonic classification theory of Riemannian 2-manifolds have been deduced from certain general principles. The present note is methodological in nature: the aim is to supplement the theory by showing that very simple counterexamples can be directly constructed.

Whereas earlier work has been devoted to the class $H^{2}$ of nonharmonic biharmonic functions, here the class $W$ of all biharmonic functions is discussed. This is of interest, since the classes $O_{W B}$ and $O_{W D}$ of Riemannian manifolds without (nonconstant) bounded or Dirichlet finite biharmonic functions are strictly contained in the corresponding classes $O_{H^{2} B}$ and $O_{H^{2} D}$, as is seen by endowing the unit disk with a suitable conformal metric. Moreover, for $W$-functions the biharmonic equation need not be reduced to the Poisson equation but can be dealt with directly.
\end{abstract}

These aspects, however, are not essential. Our sole aim is to produce simple counterexamples. In particular, the function $\log \log \left(e^{x}+a\right)$ on a horizontal strip (Theorem 4) shows immediately that there are parabolic 2-manifolds which carry $H^{2} D$-functions. We also include some examples of 3-manifolds.

1. It is well known that there are no bounded harmonic functions on a parabolic manifold. In contrast, we shall show:

THEOREM 1. There exist parabolic manifolds which carry nonconstant WB-functions.

Proof. Consider in the complex $(x, y)$-plane the strip $\{-\infty<x<$ $\infty ; 0 \leqq y \leqq 2 \pi\}$ with the lines $y=0$ and $y=2 \pi$ identified by vertical translation so as to obtain a doubly connected Riemann surface $S$. The choice of the strip instead of the punctured plane is not essential, but it will slightly simplify the computation. Clearly $S \in O_{G}$, e.g., by virtue of the modular test (cf. [7]). On the Riemannian manifold $S_{\lambda}=(S, \lambda(z)|d z|)$ with $\lambda=e^{x}$, the function $u=\cos 2 y$ is bounded biharmonic. In fact, $\Delta_{\lambda} u=e^{-2 x} \Delta \cos 2 y=-4 \cos 2 y \in H(S)$, where $\Delta_{\lambda}$ and $\Delta$ are the Laplace-Beltrami operators with respect to the metric $\lambda(z)|d z|$ and the Euclidean metric, and $H$ stands for the class of harmonic functions. Thus $S_{2} \in O_{G}-O_{W B}$. 
2. THEOREM 2. There exist hyperbolic manifolds which do not carry nonconstant WB-functions.

Proof. We shall show that the Euclidean 3 -space $E^{3}$ is such a manifold. Clearly $E^{3} \notin O_{G}$. In order to prove that $E^{3} \notin O_{W B}$, let $u \in W B\left(E^{3}\right)$. We recall that every biharmonic function in $E^{3}$ can be written as $h+r^{2} k$ with $h, k \in H\left(E^{3}\right)$ (cf. [1]), and any harmonic $h$ can be expanded in orthogonal spherical harmonics $S_{n m}(\theta, \psi)$,

$$
h=\sum_{n=0}^{\infty} r^{n} \sum_{m=1}^{2 n+1} a_{n m} S_{n m}
$$

(cf. [1] and [2]). Thus $u$ has the expansion

$$
u=\sum_{n=0}^{\infty} r^{n} \sum_{m=1}^{2 n+1}\left(a_{n m}+b_{n m} r^{2}\right) S_{n m} .
$$

We multiply both sides by $S_{n m} \sin \theta$, integrate with respect to $\theta$ and $\psi$, and conclude by the boundedness of $u$ that $a_{n m}=0$ for $n>0$, all $m$; and $b_{n m}=0$ for all $(n, m)$. Thus $u=a_{0}$.

3. THEOREM 3. There exist parabolic manifolds which do not carry nonconstant WB-functions.

Proof. Let $S^{2}$ be the strip $S_{\lambda}$ with a "cap" at $x=-\infty$, that is, we view $S_{\lambda}$ as a simply connected parabolic manifold $S^{\lambda}$ punctured at a point corresponding to $x=-\infty$. We assume that there is a $u \in W B\left(S^{\lambda}\right)$. Its restriction to $S_{\lambda}$ has the expansion

$$
u=\sum_{n=0}^{\infty} e^{n x}\left[\left(a_{n}+b_{n} e^{2 x}\right) \cos n y+\left(c_{n}+d_{n} e^{2 x}\right) \sin n y\right] .
$$

We multiply both sides by $\cos n y+\sin n y$, integrate with respect to $y$, and conclude by the boundedness of $u$ that $b_{n}=d_{n}=0$ for all $n \geqq 0$. Hence $u=\sum_{n=0}^{\infty} e^{n x}\left(a_{n} \cos n y+c_{n} \sin n y\right)$. This is the restriction to $S_{\lambda}$ of a harmonic function on $S^{\lambda}$, and we have $u=a_{0}$, hence the theorem.

That there exist hyperbolic manifolds which carry nonconstant $W B$-functions is obvious in view of the Euclidean disk.

4. We turn to the class $D$ of functions with finite Dirichlet integrals $D(u)=\int d u \wedge * d u$.

THEOREM 4. There exist parabolic manifolds which carry nonconstant WD-functions.

Proof. We shall show that the function $u=\log \log \left(e^{x}+a\right)$ is in 
$W D$ on our parabolic strip $S_{\lambda}$ with a suitable metric $\lambda(z)|d z|$. Here the constant $a>1$ is so chosen that $a \log (1+a)=1$. The Euclidean Laplacian

$$
\Delta u=\frac{e^{x}\left[e^{x}-a \log \left(e^{x}+a\right)\right]}{\left(e^{x}+a\right)^{2}\left[\log \left(e^{x}+a\right)\right]^{2}}
$$

is of the same $\operatorname{sign}$ as $x$ and has a positive derivative at $x=0$. Thus $\Delta u / x$ is well defined and positive. Let $\lambda^{2}=\Delta u / x$. On the manifold $S_{\lambda}=\left(S,(\Delta u / x)^{1 / 2}|d z|\right)$, we have $\Delta_{\lambda} u=x \in H(S)$, and therefore $u \in W$. Moreover, $D(u)$ is independent of the metric, and can be taken over $S$ :

$$
\begin{aligned}
D(u) & =\int_{S}\left(\frac{\partial u}{\partial x}\right)^{2} d x d y=2 \pi \int_{-\infty}^{\infty}\left(\frac{e^{x}}{\left(e^{x}+a\right) \log \left(e^{x}+a\right)}\right)^{2} d x \\
& <2 \pi \int_{-\infty}^{\infty} \frac{\left(e^{x}+a\right) d e^{x}}{\left(e^{x}+a\right)^{2}\left[\log \left(e^{x}+a\right)\right]^{2}}=-\left.\frac{2 \pi}{\log \left(e^{x}+a\right)}\right|_{-\infty} ^{\infty}<\infty .
\end{aligned}
$$

5. The following trivial necessary condition is a modification of a test in [3]: If $u \in W D$, then $|(u, \Delta \varphi)| \leqq K \sqrt{\overline{D(\varphi)}}$ for some constant $K$ independent of $\varphi$ and for all $\varphi \in C_{0}^{\infty}$. In fact, for $\varphi \in C_{0}^{\infty}$ with supp $\varphi$ in some regular subregion $\Omega, 0=\int_{\partial \Omega} u \wedge * d \varphi=\int_{\Omega} d u \wedge * d \varphi-$ $\int_{\Omega} u \Delta \varphi d V$ and $|(u, \Delta \varphi)|=\left|\int_{\Omega} d u \wedge * d \varphi\right|=|D(u, \varphi)| \leqq \sqrt{D(u)} \sqrt{D(\varphi)}=$

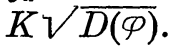

THEOREM 5. There exist hyperbolic manifolds which do not carry nonconstant $W D$-functions.

Proof. We shall show that $E^{3}$ is such a manifold. Since $E^{3} \notin O_{G}$, we only have to prove that $E^{3} \in O_{W D}$. Let $u \in W D\left(E^{3}\right)$. Expand $\Delta u=$ $h$ as in No. 2. Suppose $a_{n m} \neq 0$ for some $(n, m)$. Let $f$ be a fixed $C_{0}$ function on $[0, \infty)$ with supp $f \subset(0,1)$, and set $\rho_{t}(r)=f(r-t)$, $\varphi_{t}(r, \theta, \psi)=\rho_{t}(r) S_{n m}(\theta, \psi)$. As $t \rightarrow \infty$,

$$
\begin{gathered}
\left|\left(u, \Delta \varphi_{t}\right)\right|=\left|\left(h, \varphi_{t}\right)\right|=\mathrm{const} \int_{t}^{t+1} \rho_{t}(r) r^{n+2} d r=O\left(t^{n+2}\right), \\
D\left(\varphi_{t}\right)=\int_{E^{3}}\left[\left(\frac{\partial \varphi_{t}}{\partial r}\right)^{2}+\frac{1}{r^{2} \sin ^{2} \psi}\left(\frac{\partial \varphi_{t}}{\partial \theta}\right)^{2}+\frac{1}{r^{2}}\left(\frac{\partial \varphi_{t}}{\partial \psi}\right)^{2}\right] d V \sim O\left(t^{2}\right),
\end{gathered}
$$

and $\sqrt{D\left(\Phi_{t}\right)}=O(t)$. We conclude that $a_{n m}=0$ for all $n \geqq 0$. A fortiori $\Delta u=0$, and $u \in H D\left(E^{3}\right)$. Since $E^{3} \in O_{H D}$, we have $u=$ const.

6. THEOREM 6. There exist parabolic manifolds which do not carry nonconstant $W D$-functions.

Proof. Let $u$ be a $W D$-function on the "capped" strip $S^{\lambda}$ of No. 
3. The restriction $\Delta u \mid S_{\lambda}$ has the expansion $\Delta u=\sum_{n=0}^{\infty} e^{n x}\left(a_{n} \cos n y+\right.$ $\left.b_{n} \sin n y\right)$. Suppose $a_{n}^{2}+b_{n}^{2} \neq 0$ for some $n$. Choose the testing function $\varphi_{t}(x, y)=\rho_{t}(x)(\cos n y+\sin n y)$, with $\rho_{t}(x)$ as before. As $t \rightarrow \infty$, $\left|\left(u, \Delta \varphi_{t}\right)\right|=\left|\left(\Delta u, \varphi_{t}\right)\right|=O\left(e^{(n+2) t}\right)$ and $\sqrt{D\left(\varphi_{t}\right)}=O(1)$. Therefore, $a_{n}=$ $b_{n}=0$ for all $n$, and $u \in H D\left(S^{\lambda}\right)$. The theorem follows from $S^{\lambda} \in O_{G} \subset$ $O_{H D}$.

That there exist hyperbolic manifolds which carry nonconstant $W D$-functions is obvious in view of the Euclidean disk.

\section{REFERENCES}

1. S. Bergman and M. Schiffer, Kernel Functions and Elliptic Differential Equations, Academic Press, 1953, $432 \mathrm{pp}$.

2. M. Brelot, Éléments de la théorie classique du potentiel, (4e édition), Centre de Documentation Universitaire, Paris, 1969, 212 pp..

3. M. Nakai and L. Sario, Existence of Dirichlet finite biharmonic functions, Ann. Acad. Sci. Fenn. A.I., 532 (1973), 1-33.

4. - Existence of bounded Dirichlet finite biharmonic functions, Ann. Acad. Sci. Fenn. A.I., 505 (1972), 1-12.

5. - Biharmonic functions on Riemannian manifolds, Continuum Mechanics and Related Problems of Analysis, Nauka, Moscow, 1972, 329-335.

6. - Existence of bounded biharmonic functions, J. Reine Angew. Math., 259 (1973), 147-156.

7. L. Sario and M. Nakai, Classification Theory of Riemann Surfaces, Springer, 1970, $446 \mathrm{pp}$.

Received July 19, 1972. The work, carried out in the Summer, 1971, was sponsored by the U. S. Army Research Office-Durham, Grant DA-ARO-D-31-124-71-G20, University of California, Los Angeles.

UNIVERSITY OF CALIFornia, LOS ANGELES 


\section{PACIFIC JOURNAL OF MATHEMATICS}

\section{EDITORS}

RICHARD ARENS (Managing Editor) University of California

Los Angeles, California 90024

R. A. BeaUmont

University of Washington Seattle, Washington 98105
J. DUGUNDJI*

Department of Mathematics University of Southern California Los Angeles, California 90007

D. Gilbarg and J. Milgram Stanford University

Stanford, California 94305

\section{ASSOCIATE EDITORS}

E. F. BECKENBACH

B. H. NeUmanN

F. WOLF

K. YoSHIDA

\section{SUPPORTING INSTITUTIONS}

\section{UNIVERSITY OF BRITISH COLUMBIA CALIFORNIA INSTITUTE OF TECHNOLOGY UNIVERSITY OF CA.LIFORNIA MONTANA STATE UNIVERSITY UNIVERSITY OF NEVADA NEW MEXICO STATE UNIVERSITY OREGON STATE UNIVERSITY UNIVERSITY OF OREGON OSAKA UNIVERSITY}

UNIVERSITY OF SOUTHERN CALIFORNIA STANFORD UNIVERSITY UNIVERSITY OF TOKYO UNIVERSITY OF UTAH WASHINGTON STATE UNIVERSITY UNIVERSITY OF WASHINGTON AMERICAN MATHEMATICAL SOCIETY NAVAL WEAPONS CENTER

* C. R. DePrima California Institute of Technology, Pasadena, CA 91109, will replace J. Dugundji until August 1974. 


\section{Pacific Journal of Mathematics}

\section{Vol. 50, No. $1 \quad$ September, 1974}

Gail Atneosen, Sierpinski curves in finite 2-complexes.............. 1

Bruce Alan Barnes, Representations of $B^{*}$-algebras on Banach spaces .... 7

George Benke, On the hypergroup structure of central $\Lambda(p)$ sets ....... 19

Carlos R. Borges, Absolute extensor spaces: a correction and an

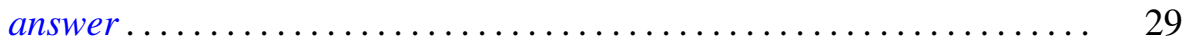

Tim G. Brook, Local limits and tripleability .................. 31

Philip Throop Church and James Timourian, Real analytic open maps .... 37

Timothy V. Fossum, The center of a simple algebra ............... 43

Richard Freiman, Homeomorphisms of long circles without periodic

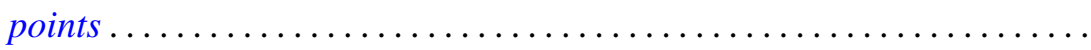

B. E. Fullbright, Intersectional properties of certain families of compact

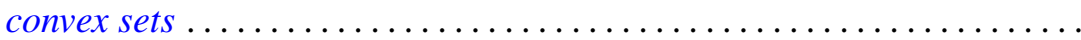

Harvey Charles Greenwald, Lipschitz spaces on the surface of the unit

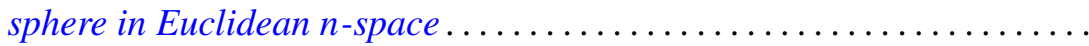

Herbert Paul Halpern, Open projections and Borel structures for

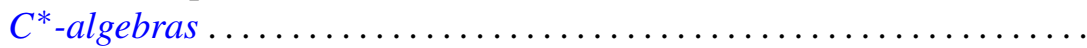

Frederic Timothy Howard, The numer of multinomial coefficients divisible

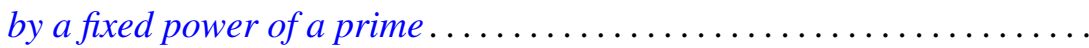

Lawrence Stanislaus Husch, Jr. and Ping-Fun Lam, Homeomorphisms of manifolds with zero-dimensional sets of nonwandering points........ 109

Joseph Edmund Kist, Two characterizations of commutative Baer rings ...

Lynn McLinden, An extension of Fenchel's duality theorem to saddle functions and dual minimax problems ................

Leo Sario and Cecilia Wang, Counterexamples in the biharmonic classification of Riemannian 2-manifolds...

Saharon Shelah, The Hanf number of omitting complete types ...

Richard Staum, The algebra of bounded continuous functions into a

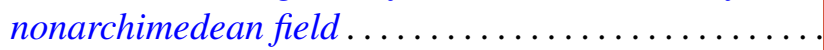

James DeWitt Stein, Some aspects of automatic continuity ..

Tommy Kay Teague, On the Engel margin

John Griggs Thompson, Nonsolvable finite groups all of whose local subgroups are solvable, $V \ldots \ldots \ldots \ldots \ldots \ldots \ldots \ldots$

Kung-Wei Yang, Isomorphisms of group extensions 